Index Copernicus Value: 71.58

ISSN (e)-2347-176x ISSN (p) 2455-0450

crossref DOI: _https://dx.doi.org/10.18535/jmscr/v6i1.172

Journal Of Medical Science And Clinical Research

IGM Publication

An official Publication of IGM Publication

\title{
Prevalence and Antibiogram of Vaginal Carriage of Group B Streptococci in Third Trimester of Pregnancy and Its Feto-Maternal Outcome
}

\author{
Authors \\ Dr Ceena.V.Netto ${ }^{1}$, Dr Ramani Bai.J.T ${ }^{2}$, Dr Geetha Bhai ${ }^{3}$ \\ ${ }^{1}$ Junior Consultant, General Hospital, Pala, Kottayam \\ ${ }^{2}$ Head of Microbiology Dept, Sree Narayana Medical College, Varkala \\ ${ }^{3}$ Head of Microbiology, Sree Gokulam Medical College and Research Foundation, Venjaramoodu \\ Corresponding Author \\ Dr Ceena.V.Netto \\ Email: ceenavnetto@gmail.com
}

\begin{abstract}
Background and Objectives: Group-B Streptococcal $(G B S)$ prevalence varies from place to place and this organism is responsible for serious infections in newborns such as septicemia and meningitis. This study was undertaken in order to understand the magnitude of this problem in pregnant women and its fetal outcome.

Methods: Two low vaginal swabs were taken from 380 antenatal women at 28 weeks and from the same cases at 37 weeks of gestation from Obstetrics \& Gynecology Department, Sree Gokulam Medical College and Research Foundation, Venjaramoodu. The two swabs were immediately transported to the laboratory for processing. Out of the two low vaginal swabs collected, one swab was used for Gram's stain and the other swab was inoculated in Todd - Hewitt broth (Oxoid Ltd) containing Nalidixic acid (15 mg/L) and Gentamicin $(8 \mathrm{mg} / \mathrm{L})$ and incubated at $37^{\circ} \mathrm{c}$ in $5 \% \mathrm{CO}_{2}$. After $24 \mathrm{hrs}$ of incubation from culture broth, subcultures were performed in 5\% sheep blood agar and Macconkey agar for isolation of GBS. Identification was done based on Gram staining, colony morphology, catalase reaction, CAMP test, carbohydrate fermentation, and Hippurate hydrolysis test. Isolates were confirmed by latex agglutination test.

Results: Of the 380 pregnant women screened, 3.2\% were colonized by GBS. GBS colonization rate was higher among pregnant women in third trimester who were $\leq 20$ years of age and primigravidae. In our study all the strains were sensitive to Penicillin, Ceftriaxone, Linezolid, Ofloxacin and Vancomycin. Resistance was observed with Erythromycin (25\%), Clindamycin (25\%).

Conclusion: As the GBS colonization rate among pregnant women in third trimester of pregnancy is low, screening for GBS as a routine component of prenatal care is a procedure of uncertain clinical value.

Keywords: Group-B Streptococcus; Colonization; Prevalence.
\end{abstract}

\section{Introduction}

Group A Streptococci had a place of pride as causative agent of important clinical diseases and syndrome till recently. Other members of this family are now coming to light as human pathogens and Group B Streptococci is topping the list since the last few decades. Group B Streptococci or Streptococcus agalactiae is a well-recognized pathogen in veterinary medicine because of its role as causative agent of bovine 
mastitis. There has been increasing interest in Group B Streptococci (GBS) due to their association with and recognition as pathogens of neonatal infections like sepsis and meningitis. ${ }^{1,2}$ Group B Streptococci are present in 15-20\% of pregnant women in lower genital tract ${ }^{3}$. Vaginal colonization by GBS during pregnancy is associated with life threatening neonatal infections acquired during passage through the birth canal, and it has been the most frequent cause of neonatal meningitis in infants ${ }^{4,5}$. Group B Streptococci has been associated with low birth weight, premature delivery, premature rupture of membranes, still birth and neonatal death suggesting that it has a marked predilection for pregnant women, fetus and neonates ${ }^{6}$. The mother's birth canal is the principle reservoir of this infectious agent for infants who develop the more severe syndrome with early onset. ${ }^{7}$

Infections in newborn occurring within the first week of life are designated early onset group B Streptococcal (EOGBS) disease. Late onset disease develops in infants after 7 days and upto 3 months of age. The measures used to prevent EOGBS disease, however do not prevent late onset GBS disease. Infants with early onset GBS disease generally present with respiratory distress, apnoea or other signs of sepsis within the first 2448 hours of life. The most common clinical manifestations of EOGBS are sepsis and pneumonia, less frequently meningitis. Mortality is higher among preterm infants compared with full term infants. Early onset infections are acquired vertically through exposure to GBS from the vagina of a colonized woman. Neonatal infection occurs primarily when GBS ascends from the vagina to the amniotic fluid after onset of labour or rupture of membranes, although GBS also can invade through intact membranes. GBS can be aspirated into the fetal lung, which in turn can lead to bacteremia. Infants who are exposed to the organism through this route can become infected with GBS during passage through the birth canal.
Late onset disease (7-90 days) occurs less frequently than EOGBS. Maternal obstetric complications are uncommon with late onset GBS disease. Transmission can be either horizontal (from other infected infants or health care workers) or vertical (from mother due to close proximity). The two most common clinical manifestations of late onset disease are meningitis and bacteremia. The mortality rate for late onset neonatal disease is $2-6 \%$ which is significantly lower than the rate of $10 \%$ for early onset infections. However, this rate has not declined in the Western countries despite the implementation of prophylactic measures.

In India very few studies have been carried out, mainly to study the prevalence of GBS infections. The GBS colonization rate in the vaginal flora of pregnant women varied from 0.47 to $23.3 \%$ as reported by various workers.

The factors controlling maternal GBS colonization and neonatal disease due to GBS are - age, number of previous pregnancies, phase of menstrual cycle, use of oral contraceptives. This study was undertaken in order to understand the magnitude of this problem in pregnant women and its fetal outcome.

\section{Materials and Methods}

Study Design: Descriptive study.

Study Setting: Department of Microbiology, Department of Obstetrics and Gynaecology, Sree Gokulam Medical College and Research Foundation, Venjaramoodu.

Study Period: Two years (December 2014 November 2016).

Study Population: Antenatal cases at 28 weeks and same cases at 35-37 weeks attending the Obstetrics and Gynaecology OP of Sree Gokulam Medical College and Research Foundation.

Sample Size: 380 antenatal cases.

Inclusion Criteria: Antenatal cases at 28 weeks and same cases at 35-37 weeks attending the Obstetrics and Gynaecology OP of Sree Gokulam Medical College and Research Foundation. 


\section{Exclusion Criteria}

First \& second trimester antenatal cases.

\section{Methodology}

\section{Sample collection}

Two low vaginal swabs were taken prior to the first pelvic examination from 380 antenatal women at 28 weeks and from the same cases at 35-37 weeks of gestation from Obstetrics \& Gynaecology Department, Sree Gokulam Medical College and Research Foundation, Venjaramoodu. Detailed history of each case was taken, which has been mentioned in the proforma. The swabs were immediately transferred to the laboratory without delay for processing. In case of any delay appropriate transport systems (Amie's or Stuart's) were used.

\section{Sample processing}

Out of the two low vaginal swabs collected, one swab was used for Gram's stain and the other swab was inoculated in Todd-Hewitt broth (Oxoid Ltd) containing Nalidixic acid $(15 \mathrm{mg} / \mathrm{L})$ and Gentamicin $(8 \mathrm{mg} / \mathrm{L})$ and incubated at $37^{\circ} \mathrm{c}$ in $5 \%$ $\mathrm{CO}_{2}$. After $24 \mathrm{hrs}$ of incubation from culture broth, subcultures were performed in 5\% sheep blood agar (SBA) and MacConkey agar for isolation of GBS. The blood agar plate was incubated in a candle jar for 18 to 24 hours at $37^{\circ} \mathrm{C}$ and examined for the presence of $\beta$ hemolytic Streptococci. Broth cultures showing no visible turbidity after overnight incubation were further re-incubated and then sub cultured after 48 hours on sheep blood agar. The colony characters such as shape, size, colour, margin, consistency, elevation and zone of hemolysis, etc. were noted .

The presumptive diagnosis of GBS was based on the following:

\section{Direct smear examination (Gram staining) :} Gram stained smear of the vaginal swab were examined for the presence of gram positive cocci in pairs, short chains or long chains.

\section{Procedure}

1. Smear was made from the swab on a clean glass slide, air dried and heat fixed.
2. It was flooded with $1 \%$ crystal violet for 1 minute and washed with water.

3. Smear was flooded with Gram's iodine for $1 \mathrm{~min}$ and washed with water.

4. Decolourization with acetone for 3 seconds.

5. Smear was counter stained with dilute Carbol fuchsin for 30 seconds.

6. Smear was washed, air dried and examined under the oil immersion lens.

\section{Interpretation}

In 12 smears epithelial cells, few pus cells and gram positive cocci were seen in pairs, short and long chains. In the remaining smears there were only epithelial cells and normal vaginal flora.

2. Culture on blood agar : showed translucent to opaque, flat, glossy colony with narrow zone of beta hemolysis.

3. Culture on Macconkey agar : showed magenta red colonies.

\section{Catalase test}

The presence of catalase enzyme in the test isolate is detected using 3\% hydrogen peroxide. Place one drop of $\mathrm{H}_{2} \mathrm{O}_{2}$ on a slide containing a suspension of colony Prompt effervescence indicates catalase production. All the 12 isolates were negative for catalase test.

\section{Quality control}

Positive control: Staphylococcus aureus ATCC 25923.

Negative control: Enterococcus faecalis ATCC 29212.

\section{Hippurate hydrolysis test}

- $1 \%$ solution of sodium hippurate is prepared and $0.4 \mathrm{ml}$ volume is dispensed in a capped tube.

- The tube is inoculated heavily with the organism to be tested. The suspension should become milky.

- The tube is incubated at $37^{\circ} \mathrm{C}$ for 2 hours.

- $0.2 \mathrm{ml}$ of ninhydrin reagent is added and further incubated for $10-15$ minutes at $37^{\circ} \mathrm{C}$.

\section{Interpretation}

If the test is positive, there is development of deep purple colour, which is seen in GBS. If the test is negative, there will either be no colour change or 
there is development of slightly yellow-pink colour. All the isolates were positive for Hippurate hydrolysis test.

\section{Quality control:}

Positive control: Streptococcus agalactiae.

Negative control: Streptococcus pyogenes.

\section{CAMP Test}

- $\square$-hemolytic Staphylococcus aureus (NCTC 7428) is streaked in a straight line across the centre of 5\% sheep blood agar plate.

- Known positive (group-B Streptococcus) and negative (group-A Streptococcus) controls are inoculated in a single straight line (1 cm apart from Staphylococcus aureus streak) at $90^{\circ}$ angle to Staphylococcus streak.

- The test organism is also streaked across the plate perpendicular to the Staphylococcus aureus streak, leaving about $1 \mathrm{~cm}$ space in between the two streaks.

- The plate is incubated overnight at $37^{\circ} \mathrm{C}$ in candle jar or $\mathrm{CO}_{2}$ incubator.

\section{Interpretation}

Positive: Positive readings may occur at 5-6 hours after incubation. With group BStreptococci an area of increased lysis appears at the junction of two streaks indicated by an arrow head zone of hemolysis.

Negative: No enhancement of hemolysis.

Quality control:

Positive control: group B Streptococcus.

Negative control: group A Streptococcus.

\section{Carbohydrate fermentation test}

Fermentation of carbohydrates was studied in peptone water as the basal medium with bromocresol purple indicator and 1\% sugar. The base is dispensed, sterilized by autoclaving and cooled. 1\% sugar solution is prepared by dissolving 1gm sugar in $100 \mathrm{ml}$ base. Adjust the ph to 7.1-7.3. Then dispense $3 \mathrm{ml}$ amounts and sterilize by steaming for 30 minutes. Fermentation of arabinose, mannitol, lactose, trehalose, sorbitol, sucrose, pyruvate and raffinose were done. Inoculate two to three colonies of the test strain into each of the sugars and incubate overnight at $37^{\circ} \mathrm{c}$. A colour change from violet purple to yellow indicates positive reaction.

9. Latex agglutination test for serologic grouping of $\beta$ haemolytic Streptococci

The cell-wall grouping antigen is extracted from the GBS cell wall enzymatically, and the extract is subsequently reacted with latex beads to which group specific antibodies are bound.

\section{Procedure}

1. For extracted antigen: Use a sterilized loop to transfer well isolated GBS colonies to a small test-tube containing extraction solution and emulsify them. Incubate the emulsion at $35^{\circ} \mathrm{c}$.

2. Place one drop of the antibody-coated particles on the slide.

3. Place one drop of the antigen suspension beside the antibody-coated particles.

4. Mix the two drops on the slide and spread in a square.

5. Rotate the slide by hand in a steady circular motion for one minute. Take care that the mixture does not spill outside the boundaries of the square.

6. Examine the slide macroscopically for agglutination after the time specified in the manufacturer's instructions. For best visibility hold the slide near a bright light and view against a dark background.

\section{Interpretation}

A positive result is recorded when the antigen mixed with the antibody shows agglutination, i.e. the suspension shows clumping or is granular to the point of curdling. Agglutination is best seen by tilting the slide slightly so that the fluid drains down towards the lower boundary of the square.

10. Antimicrobial sensitivity of the GBS was done by the disc diffusion technique (Kir by-Bauer disk diffusion method).

Procedure 
- Fresh sub-cultures of GBS were used after overnight growth (16 hours) on blood agar plate.

- The inoculum was prepared by suspending 35 colonies in sterile saline to achieve a turbidity of $0.5 \mathrm{McFarland}$ standard.

- A sterile cotton swab was dipped into the bacterial suspension, elevated above the liquid and rotated several times against the inside wall of the tube to remove excess of the inoculum.

- This swab was streaked evenly in three different directions on the surface of $5 \%$ sheep blood agar.

- The plate was rotated through an angle of $60^{\circ}$ after each application.

- The plate was allowed to dry for a few minutes at room temperature with the lid closed. The antimicrobial discs was placed on the inoculated plates using a pair of sterile forceps. 4 discs were placed on a $100 \mathrm{~mm}$ plate. Plates were incubated aerobically at $35^{0}$ c.

- After 18-24 hours of incubation, the diameter of clear zone around the disk was measured under transmitted light with measuring scale and results interpreted as susceptible, intermediate or resistant as per CLSI criteria.

Following drugs were tested:

- Penicillin (10 IU/disc).

- Erythromycin $(15 \mu \mathrm{g} /$ disc $)$.

- Clindamycin $(2 \mu \mathrm{g} /$ disc $)$.

- Ceftriaxone $(30 \mu \mathrm{g} / \mathrm{disc})$.

- Co-trimoxazole $(25 \mu \mathrm{g} / \mathrm{disc})$.

- Ofloxacin $(5 \mu \mathrm{g} / \mathrm{disc})$.

- Linezolid (30 $\mu \mathrm{g} / \mathrm{disc})$.

- Vancomycin $(30 \mu \mathrm{g} /$ disc $)$.

Table-6: Antimicrobial Agents and Zone Interpretation according to CLSI Guidelines

\begin{tabular}{|l|c|c|c|c|c|}
\hline Sl.No & $\begin{array}{c}\text { Antimicrobial } \\
\text { Agents }\end{array}$ & $\begin{array}{c}\text { Disc } \\
\text { concentration }\end{array}$ & Sensitive & Intermediate & Resistant \\
\hline 1 & Penicillin & 10 units & $\geq 24$ & - & - \\
\hline 2 & Erythromycin & $15 \mu \mathrm{g}$ & $\geq 21$ & $16-20$ & $\leq 15$ \\
\hline 3 & Clindamycin & $2 \mu \mathrm{g}$ & $\geq 19$ & $16-18$ & $\leq 15$ \\
\hline 4 & Ceftriaxone & $30 \mu \mathrm{g}$ & $\geq 24$ & - & - \\
\hline 5 & Ofloxacin & $5 \mu \mathrm{g}$ & $\geq 16$ & $13-15$ & $\leq 12$ \\
\hline 6 & Linezolid & $30 \mu \mathrm{g}$ & $\geq 21$ & - & - \\
\hline 7 & Vancomycin & $30 \mu \mathrm{g}$ & $\geq 17$ & - & - \\
\hline
\end{tabular}

\section{Fetomaternal Outcome}

After delivery APGAR score at 1 and 5 min, birth weight, congenital anomalies, immediate complications and birth injuries, signs of asphyxia, meconium aspiration, sepsis and other associated complications were recorded. The babies were followed up in the post natal period. Neonatal morbidity and mortality were noted. Mothers were watched for third stage complications like postpartum haemorrhage and retained placenta. They were followed up in puerperal period. Vital parameters like temperature, pulse and blood pressure were frequently monitored. Women were specifically asked for foul smelling lochia and the presence of febrile morbidity. Maternal morbidity like puerperal sepsis, urinary and respiratory tract infection and wound infection were looked for.

Both mother and baby were followed up till their stay in the hospital.

\section{Results}

A total of 380 antenatal cases were included in this study which was conducted over a period of two years from December 2014 - November 2016 at Sree Gokulam Medical College and Research Foundation, Venjaramoodu, Thiruvananthapuram.

Table-7: Occurrence of GBS in third trimester of pregnancy (28 weeks and 35-37 weeks)

\begin{tabular}{|l|c|}
\hline Total cases studied & $\begin{array}{c}\text { GBS positive mothers } \\
\text { No (\%) }\end{array}$ \\
\hline 380 & 12 \\
& $(3.2 \%)$ \\
\hline
\end{tabular}


Out of 380 pregnant women in third trimester, 12 (3.2\%) were identified as Group-B Streptococci positive.

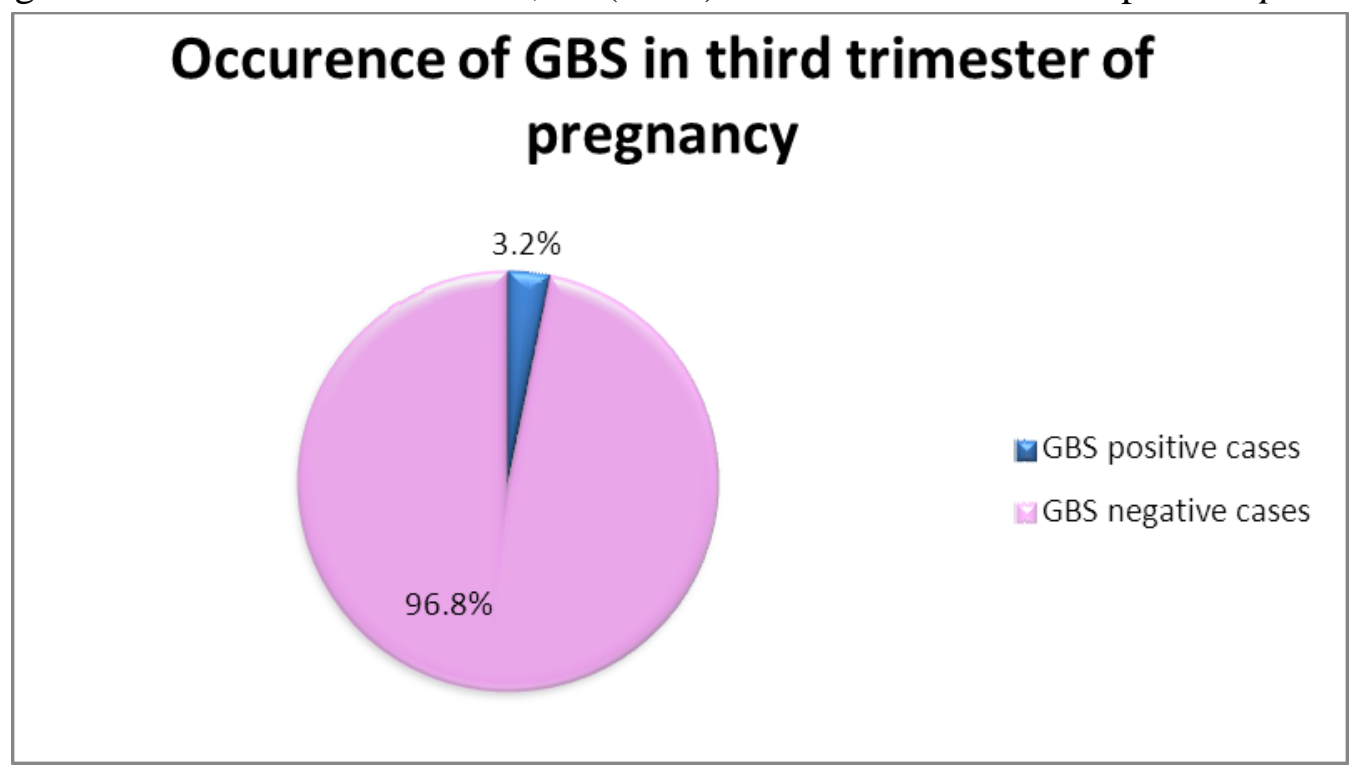

(28 weeks and 35-37 weeks)

Figure- 1 : Occurrence of GBS in third trimester of pregnancy

The occurrence of group-B Streptococci was studied in relation to:

1. Age

2. Number of pregnancies.

Table-8 : Occurrence of GBS in different age groups

\begin{tabular}{|l|c|c|c|c|}
\hline Age group & No. of mothers & GBS negative & GBS positive & GBS positive Percent \\
\hline$\leq 20$ years & 58 & 53 & 5 & $8.6 \%$ \\
\hline $21-25$ years & 171 & 167 & 4 & $2.3 \%$ \\
\hline $26-30$ years & 107 & 105 & 2 & $1.9 \%$ \\
\hline$>30$ years & 44 & 43 & 1 & $2.3 \%$ \\
\hline Total & $\mathbf{3 8 0}$ & $\mathbf{3 6 8}$ & $\mathbf{1 2}$ & $\mathbf{3 . 2 \%}$ \\
\hline Chi square $\rightarrow 6.728$ p-value $\rightarrow 0.081 . N S$ &
\end{tabular}

Most of the isolates were from the age group $\leq 20$ years $(8.6 \%)$, followed by age groups $21-25 \mathrm{yrs}(2.3 \%)$ and $>30 y r s(2.3 \%)$. There is no association between age of mother and GBS colonization.

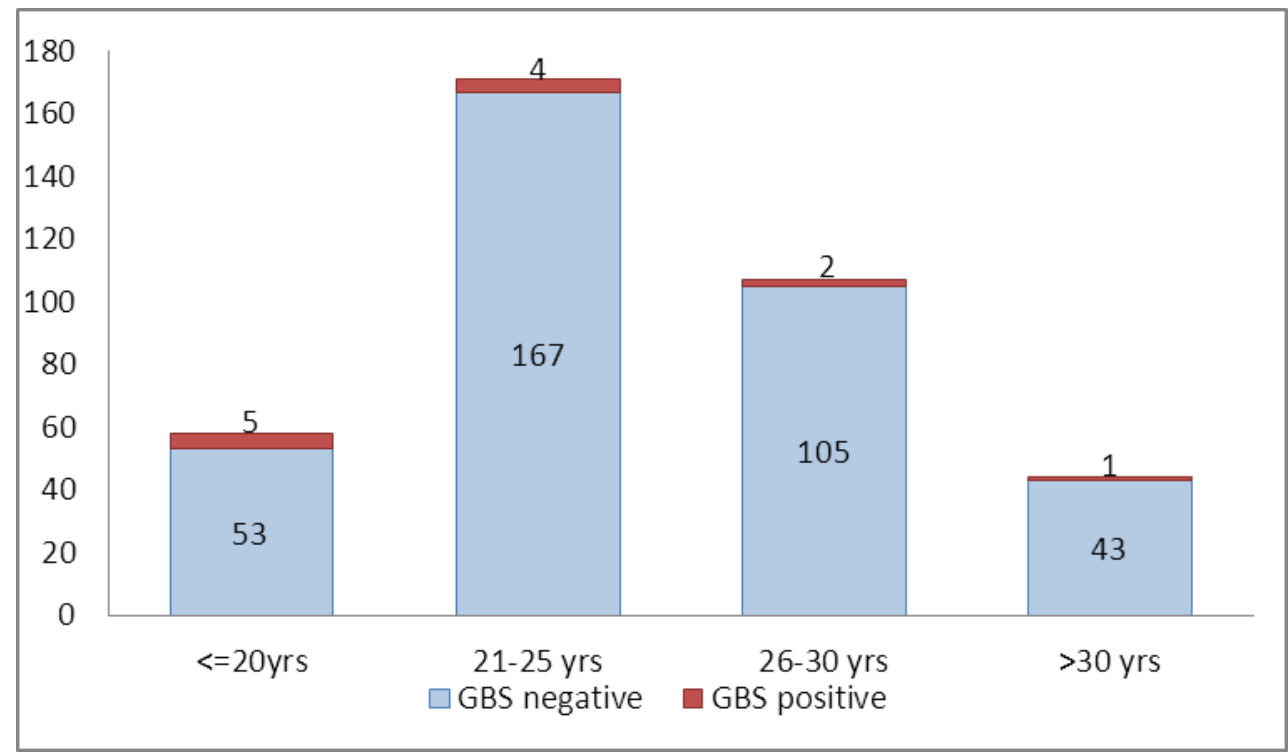

Figure-2 Occurrence of GBS in Different Age Groups 
Table-9 : Relationship between GBS colonization and parity

\begin{tabular}{|l|c|c|c|c|}
\hline Subject status & No. of subjects & GBS negative & GBS positive & $\begin{array}{c}\text { GBS positive } \\
\text { Percent }\end{array}$ \\
\hline Primi gravidae & 210 & 201 & 9 & $4.3 \%$ \\
\hline Second gravidae & 119 & 116 & 3 & $2.5 \%$ \\
\hline Third gravidae & 35 & 35 & 0 & $0 \%$ \\
\hline Multi gravidae & 16 & 16 & 0 & $0 \%$ \\
\hline Total & $\mathbf{3 8 0}$ & $\mathbf{3 6 8}$ & $\mathbf{1 2}$ & $\mathbf{3 . 2 \%}$ \\
\hline Chi-square:2.694, p-value $0.441 \rightarrow$ NS
\end{tabular}

Most of the isolates were from primi gravidae (4.3\%) followed by second gravidae (2.5\%). By applying Chisquare test, no significant association is observed between GBS colonization and parity.

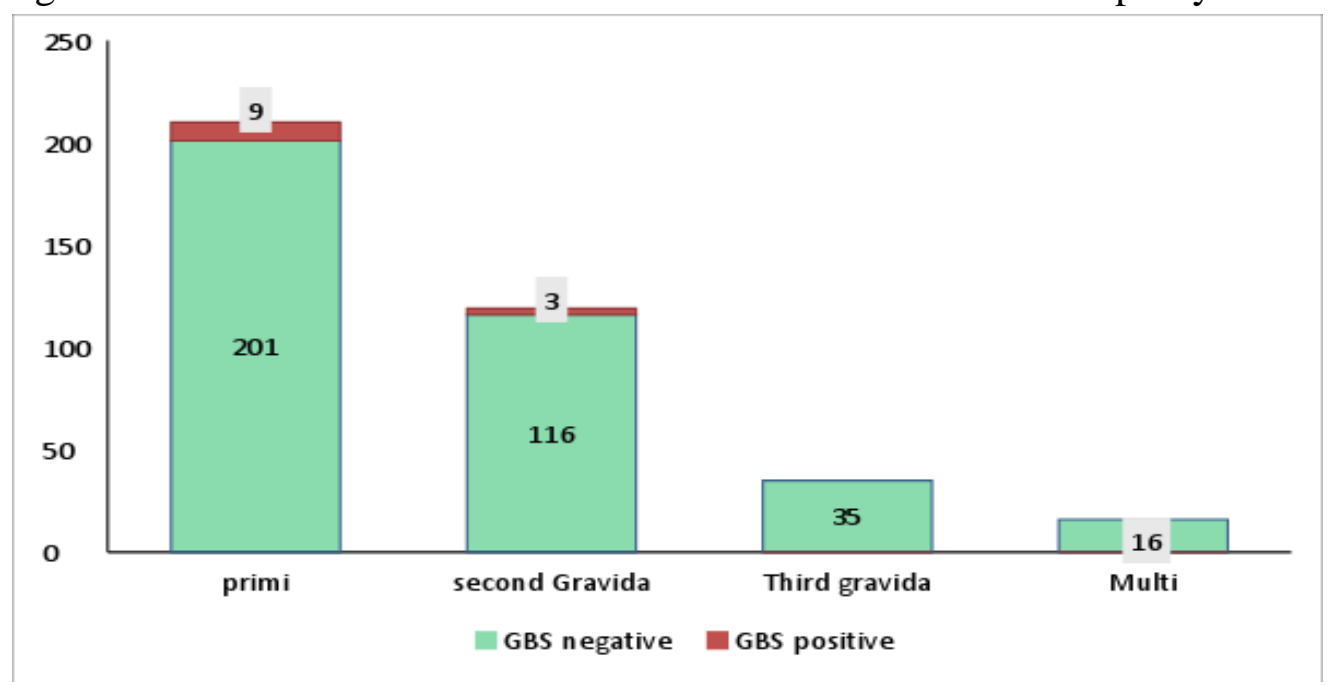

Figure-3 : Relationship between GBS Colonization and Parity

Table-10: Antibiotic Sensitivity pattern of group B Streptococci isolated in this study

\begin{tabular}{|l|c|c|c|c|}
\hline Antibiotic & $\begin{array}{c}\text { Total } \\
\text { sensitive }\end{array}$ & GBS (\%) & $\begin{array}{c}\text { No. of } \\
\text { Resistant }\end{array}$ & Percent \\
\hline Penicillin & 12 & 100.00 & 0 & 0.00 \\
\hline Ceftriaxone & 12 & 100.00 & 0 & 0.00 \\
\hline Clindamycin & 9 & 75.00 & 3 & 25.00 \\
\hline Erythromycin & 9 & 75.00 & 3 & 25.00 \\
\hline Cotrimoxazole & 0 & 0.00 & 12 & 100.00 \\
\hline Ofloxacin & 12 & 100.00 & 0 & 0.00 \\
\hline Linezolid & 12 & 100.00 & 0 & 0.00 \\
\hline Vancomycin & 12 & 100.00 & 0 & 0.00 \\
\hline
\end{tabular}

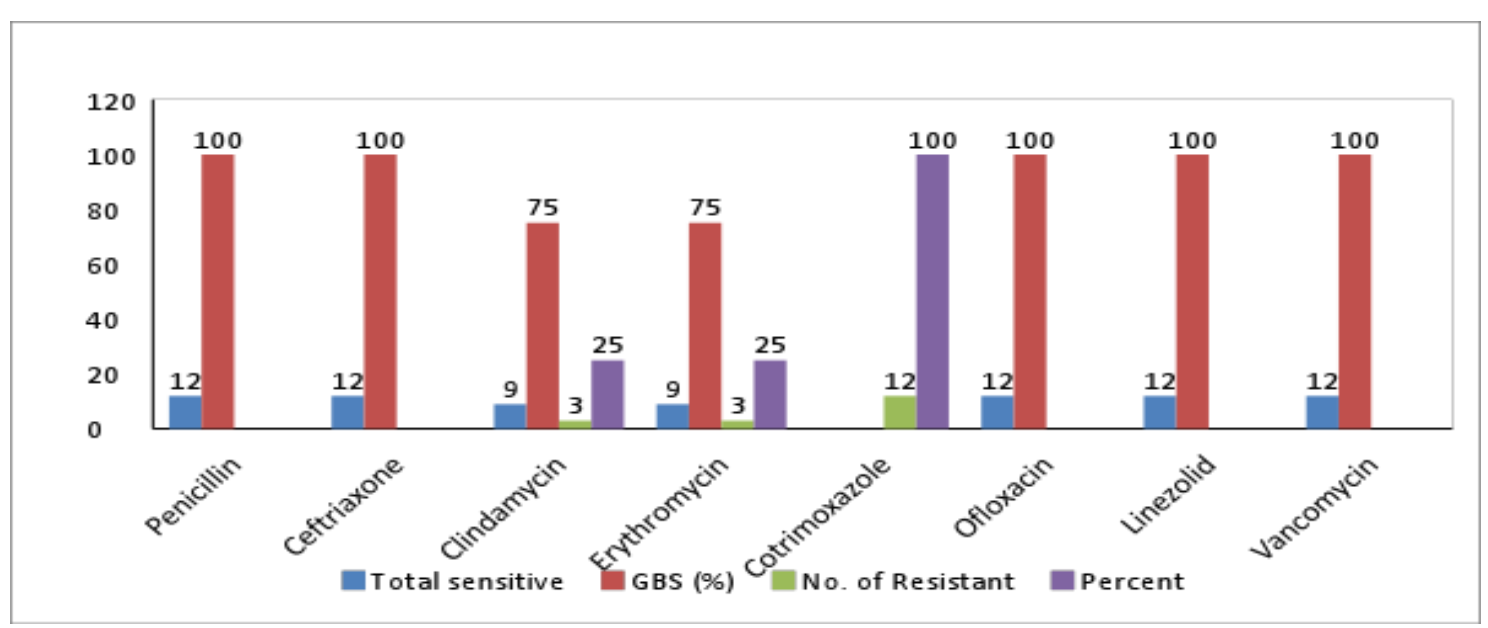

Figure-4 Antibiotic Sensitivity pattern of group B Streptococci isolated in this study 
A total of 380 antenatal cases were screened. Only 12 cases were colonized with GBS. Among the 12 cases 2 cases presented with premature rupture of membranes (16.7\%). All GBS positive cases were detected during 35-37 weeks gestation. The same cases were GBS negative at 28 weeks gestation. GBS positive cases were given prophylactic antibiotics. Neonates of the GBS positive mothers were normal except for two babies who had low birth weight $(16.7 \%)$. Low birth weight maybe due to some other cause other than maternal group B colonization. There were two cases of neonatal meningitis caused by group B Streptococci. Antenatal mothers of the above two cases were negative during GBS screening at 28 weeks and $35-37$ weeks gestation.

There were no significant correlation between GBS colonisation and parity, age of screened antenatal mothers. The other maternal risk factors including prolonged rupture of membranes, history of intrapartum fever and low birth weight also did not correlate with GBS colonization in pregnant women.

\section{Discussion}

Two low vaginal swabs were taken from 380 antenatal women at 28 weeks and from the same cases at 35-37 weeks of gestation from Obstetrics and Gynaecology Department, Sree Gokulam Medical College and Research Foundation, Venjaramoodu.

In our study the prevalence rate of GBS colonization in antenatal women was $3.2 \%$ at 35 37 weeks of gestation. Our statistics almost correlate with the results of Mhasker Rita et al of Banglore who have reported a vaginal GBS colonization rate of $1.62 \%{ }^{8}$. Kulkarni et al in Maharashtra also has observed a low rate $(2.52 \%)$ of GBS colonization ${ }^{9}$. In a study conducted at Saudi Arabia, El Kersh et al observed a rate of $2.6 \%$ GBS vaginal colonization among 151 cases who were negative for GBS colonization in earlier visits ${ }^{10}$.

Table-11 : Low GBS colonization rates reported in different studies

\begin{tabular}{|l|c|c|c|c|}
\hline Reference No & Place & $\begin{array}{c}\text { Year of } \\
\text { isolation }\end{array}$ & $\begin{array}{c}\text { Sample } \\
\text { size }\end{array}$ & $\begin{array}{c}\text { Colonization } \\
\text { rate }\end{array}$ \\
\hline Kulkarni et al $^{9}$ & India(Maharashtra) & $1998-1999$ & 317 & $2.52 \%$ \\
\hline El Kersh et al $^{10}$ & Saudi Arabia & $2000-2001$ & 151 & $2.6 \%$ \\
\hline Mhasker Rita et al $^{8}$ & India(Banglore) & $2003-2004$ & 741 & $1.62 \%$ \\
\hline Present study & India(Kerala) & $2014-2016$ & 380 & $3.2 \%$ \\
\hline
\end{tabular}

Table-12 : High GBS colonization rates reported in different studies

\begin{tabular}{|c|c|c|c|c|}
\hline Reference No & Place & Year of isolation & $\begin{array}{c}\text { Sample } \\
\text { size }\end{array}$ & $\begin{array}{c}\text { Colonization } \\
\text { rate }\end{array}$ \\
\hline Regan et al ${ }^{11}$ & USA & 1984-1989 & 13,646 & $21 \%$ \\
\hline Motlova et al ${ }^{12}$ & Czech Republic & $2001-2002$ & 586 & $29.3 \%$ \\
\hline Nwachukwu et al ${ }^{77}$ & Nigeria & $2002-2003$ & 200 & $9.0 \%$ \\
\hline Orrett $^{78}$ & Trinidad & 2003 & 201 & $32.9 \%$ \\
\hline Elbaradie et al $^{79}$ & Egypt & $2006-2007$ & 95 & $17.9 \%$ \\
\hline
\end{tabular}

Regan et al of United States reported a high colonization rate of $21 \%{ }^{11}$. Similarly a very high GBS colonization rate was identified in Czech Republic by J Motlova et al (29.3\%), Nwachukwu et al of Nigeria $(9.0 \%)$, Orett FA in Trinidad $(32.9 \%)$ and Elbaradie et al $(17.9 \%)$ from Egypt in their respective studies $12,13,14,15$. High rates of GBS colonization were detected among Saudi women $(25.7 \%){ }^{16}$
Most studies in India detected only $1.5 \%-2.5 \%$ of GBS colonization among Indian women which almost correlate with our study. The reasons for varying results may be attributed to the fact that maternal GBS colonization varies from place to place. Other factors that may have contributed to this variation include socioeconomic factors, variation in the technique of collection of samples, local application of antibiotic cream before collection of samples. Ethnic and genetic factors 
might play a role in variation of the rates of infection with GBS.

Most of our isolated strains were from primigravidae $(4.3 \%)$ followed by second gravidae $(2.5 \%)$. Similar findings were observed by Anthony et al (1978) that genital colonization was less frequent in women who were multigravidae $^{17}$.

Yow et al (1980) reported a higher colonization rate in the primigravidae than multigravidae women which also coincides with our findings ${ }^{18}$. Vinay Hajare of Karnataka also observed a higher rate of colonization in primigravidae than multigravidae ${ }^{19}$.

In a study from the West Indies colonization rates were found to be significantly greater among multigravida women than primigravida women. Similarly in studies done by Vijayan Sharmila in Pondicherry multigravida women were more often associated with GBS colonization ${ }^{20}$. However in another study involving Turkish pregnant women parity was observed to be unrelated to GBS carriage. Whereas according to Beachler and Baker (1979) no differences were found with colonized and non-colonized women with respect to age, race, marital status or parity ${ }^{21}$. Regan et al described GBS carriage as more common among older women and women of lower parity ${ }^{11}$. In the present study most of the isolated strains were from cases belonging to age group less than or equal to 20 years $(8.6 \%)$ followed by the age group of 21-25 years (2.3\%) and $>30$ yrs(2.3\%), thus in the present study, most of the GBS colonized pregnant women were from teenage and younger age group. These findings are in correlation with that of Baker et al (1977), Anthony et al (1978) and Collado et al (1981), the reasons for the predisposition of women younger than 21 years of age to vaginal colonization with GBS is less apparent ${ }^{17,22}$. In a study conducted by Tupili Ramya at Tirupathi most of the isolated strains were from cases belonging to age group less than and equals to 20 years followed by the age group of 21-25 years ${ }^{23}$. This study correlates with our study.
Our findings are in correlation with that of Vinay Hazare, et al (2012) of Karnataka, the reasons for the predisposition of women younger than 21 years of age to vaginal colonization with GBS is less apparent ${ }^{19}$. This relationship could be the result of age related development of local or humoral immunological responses that interfere with mucosal attachment and/ or persistence of GBS.

It seems that age is one of the factor for GBS colonization as observed by various workers. Among non-pregnant and pregnant women (1978) Anthony et al found that genital colonization of GBS was significantly higher in teenagers than those over 20 years of age ${ }^{17}$. Collado et al (1981) also reported a higher colonization rate in the youngest age group $<20$ years $^{22}$ but Yow et al (1980) found no relationship between colonization and age $^{18}$. The studies of GBS antibiotic prophylaxis were directed towards eradicating GBS colonization in pregnant women during the last trimester.

In each of these studies, colonization was reduced when antibiotics were administered but reemerged soon after treatment was discontinued. Only one study, that of Merenstein et al (1980), has shown a significant reduction in maternal and infant colonization rates in women treated with Penicillin $^{24}$.

In our study all the strains were sensitive to Penicillin, Ceftriaxone, Linezolid, Ofloxacin and Vancomycin. Resistance was observed with Erythromycin (25\%), Clindamycin (25\%). Currently Penicillin G (a beta lactam antibiotic) is the preferred treatment for GBS infection as it has a narrower spectrum than Ampicillin. Many studies have stated that GBS isolates were all sensitive to Penicillin and Ampicillin. In separate studies conducted by Arora et al, Kishore et al, Vinay Hazarae et al, Chen et al, Schoening T E et al in Germany all GBS isolates were sensitive to Penicillin 19,25,26. In contrast de Azavedo et al(2001) of Canada reported that 1 out of 178 GBS invasive strains were resistant to Penicillin $^{27}$. Simoes et al (2004) in his study of 52 
GBS isolates found reduced sensitivity to Penicillin 8/52(15.4\%), Ampicillin 9/52 (17.3\%), Ciprofloxacin 14/52 (26.9\%) and Nitrofurantoin $1 / 52(1.9 \%)^{28}$. In 1999, Mercer investigated 719 GBS strains that were isolated from neonates with EOGBS disease and reported that $96(13.4 \%)$ of those strains were resistant to Ampicillin ${ }^{29}$.

An alternative to the beta-lactam antibiotics is the treatment of GBS colonization/infection using antimicrobials which inhibit protein synthesis. To date many GBS strains resistant to Erythromycin and Clindamycin have been reported.In our study out of 12 GBS isolates 3 (25\%) were resistant to both Erythromycin and Clindamycin. In one Australian study of 250 isolates, Stylianopoulos et al(2002) reported a $2.8 \%$ resistance to Erythromycin $^{30}$ while a New Zealand study of 177 isolates by Werno and Murdoch (2003) reported Erythromycin (6\%) and Clindamycin (15\%) resistance (Table-13). ${ }^{31}$ In contrast, a number of studies have been reported in USA and up to $32 \%$ of GBS isolates have been reported as being resistant to Erythromycin while upto $21 \%$ of GBS isolates were reported as being resistant to Clindamycin (Table-13) ${ }^{27,28,32,33}$. Schoening T E et al reported that out of 338 GBS isolates Erythromycin resistance was $11 \%{ }^{26}$.
In Canada the resistance rates to Erythromycin and Clindamycin have been recorded as high as $17 \%$ and 26\% respectively (Table-13) (2,34 $^{32}$.Turkey, England/Wales, Portugal, Germany, South America and Greece have all reported on Erythromycin and Clindamycin resistance (Table$13)^{35,36.37,38,39,40,41}$. Turkey has reported two very high rates of Erythromycin resistance at $21.2 \%$ and $22.4 \%$ (Table-13) $^{35,36,40}$. Andrews et al, 2000 of USA also reported a Erythromycin resistance rate of $22 \%$ among GBS isolates (Table-13). ${ }^{42}$ Due to increase in resistance for antimicrobials, Erythromycin and Clindamycin cannot be used as a reliable alternative treatment for women colonized with GBS who have a high risk of Penicillin anaphylaxis.

Resistance to Tetracycline has also been reported in New Zealand, Canada, UK/Wales, Portugal and Argentina and the rates range from $72.4 \%$ to $91 \%$ (Table-13). ${ }^{31,37,39}$ In a study done by Lakshmi et al(1998) high degree of resistance was seen with Tetracycline $(87.8 \%)$ and with Kanamycin $(90.9 \%)$. Studies have also found that the incidence of GBS resistant strains differs between countries.

Table-13 : GBS Resistance to Antibiotics in various studies ${ }^{110}$

\begin{tabular}{|c|c|c|c|c|c|c|}
\hline Year & Reference & Location & Isolates & $\begin{array}{l}\text { Erythro } \\
\text { mycin \% }\end{array}$ & $\begin{array}{l}\text { Clinda } \\
\text { mycin \% }\end{array}$ & $\begin{array}{l}\text { Tetracycl } \\
\text { ine } \%\end{array}$ \\
\hline$<2002$ & $\begin{array}{l}\text { Stylianopoulos et al, } \\
2002^{30}\end{array}$ & $\begin{array}{l}\text { Australia, } \\
\text { Melbourne }\end{array}$ & 250 & 2.8 & $*$ & $*$ \\
\hline$<2002$ & $\begin{array}{c}\text { Werno \& Murdoch, } \\
2003^{31}\end{array}$ & $\begin{array}{c}\text { New } \\
\text { Zealand }\end{array}$ & 177 & 6 & 15 & 84 \\
\hline$<2004$ & Simoes et al, $2004^{28}$ & USA & 52 & $*$ & 19 & $*$ \\
\hline$<2004$ & Andrews et al, $2000^{42}$ & USA & $<182$ & 22 & 7 & $*$ \\
\hline 2000 & Sited in James, $2001^{33}$ & Ohio & $*$ & 15 & 21 & $*$ \\
\hline & & Rhode & & 25 & & \\
\hline 1997 & $\begin{array}{l}\text { Daley and Garland, } \\
2004^{32}\end{array}$ & Island & $*$ & 32 & 6.9 & $*$ \\
\hline 1999 & $\begin{array}{c}\text { de Azavedo et al, } \\
2001^{27}\end{array}$ & California & 178 & & 12 & $*$ \\
\hline$<2004$ & $\begin{array}{c}\text { Desjardins et al, } \\
2004^{34}\end{array}$ & Canada & 338 & 17 & 26 & \\
\hline 1999 & $\begin{array}{l}\text { Daley and Garland, } \\
\qquad 2004^{32}\end{array}$ & & 178 & 14 & 7 & $*$ \\
\hline$<2004$ & $\begin{array}{c}\text { Figueira-Coelho et } \\
\text { al.,2004 } \\
\end{array}$ & $\begin{array}{l}\text { England/ } \\
\text { Wales }\end{array}$ & 353 & 4 & $*$ & 91 \\
\hline
\end{tabular}




\begin{tabular}{|l|c|c|c|c|c|c|}
\hline$<2004$ & Fluegge et al, 2004 $4^{38}$ & Germany & 296 & 10.1 & 5.7 & $*$ \\
\hline$<2003$ & Tsolia et al, 2003 $^{41}$ & Greece & $*$ & 4.5 & 6 & $*$ \\
\hline $\begin{array}{l}1999- \\
2002\end{array}$ & $\begin{array}{c}\text { Figueira-Coelho et al, } \\
2004^{37}\end{array}$ & Portugal & 252 & 10.7 & 9.9 & 75.4 \\
\hline$<2003$ & Lopardo et al, 2003 & $\begin{array}{c}\text { South } \\
\text { America }\end{array}$ & $*$ & 5.2 & 1.7 & 72.4 \\
\hline$<2004$ & $\begin{array}{c}\text { Acikgoz et al, 2004 } \\
\text { (35 } \\
\text { Arisoy et al, 2003 }\end{array}$ & $\begin{array}{c}\text { Turkey } \\
\text { Radhakrishnan et al, } \\
1995^{40}\end{array}$ & 156 & 22.4 & $*$ & $*$ \\
\hline $\begin{array}{l}\text { 2014- } \\
2016\end{array}$ & $\begin{array}{c}\text { Present study } \\
\text { India } \\
\text { (Kerala) }\end{array}$ & 12 & 25 & 25 & $*$ \\
\hline
\end{tabular}

Note: Information that has not been reported or tested is represented by ${ }^{e} *$,

The other maternal risk factors including prolonged rupture of membranes, history of intrapartum fever and low birth weight did not correlate with the GBS colonization in neonates. The lack of association between these potential risk factors with neonatal GBS colonization is in contrast with findings from a study done by Orrett FA et al which associated such factors with an increased risk of vertical transmission ${ }^{14}$. The lack of association with these factors can possibly be explained by the fact that number of participants in this study with such risk factors were small and this may have decreased the power of the study.

\section{Conclusion}

The present study was done at Sree Gokulam Medical College and Research Foundation. Two low vaginal swabs were taken from 380 antenatal women at 28 weeks and from the same cases at 35-37 weeks of gestation from Obstetrics \& Gynaecology Department, during December 2014 - November 2016.

The following conclusions was derived from the present study.

- No GBS isolates were obtained from vaginal swabs taken at 28 weeks of gestation.

- Out of 380 pregnant women in third trimester (35-37weeks), 12 (3.2\%) were identified as Group-B Streptococci positive.

- Most of the isolates were from the age group $\leq$ 20 years $(8.6 \%)$, followed by age groups 21 $25 \mathrm{yrs}(2.3 \%)$ and $>30 \mathrm{yrs}(2.3 \%)$.

- Most of the isolates were from primi gravidae $(4.3 \%)$ followed by second gravidae $(2.5 \%)$.
- All GBS isolates were sensitive to Penicillin, Ceftriaxone, Vancomycin, Ofloxacin and Linezolid, $75 \%$ of isolates were sensitive to Erythromycin and Clindamycin.

The other maternal risk factors including prolonged rupture of membranes, history of intrapartum fever and low birth weight did not correlate with the GBS colonization in neonates. No significant correlation was observed between maternal age, parity and GBS colonization.

The isolation frequency of GBS among pregnant women and neonates call for further study to elucidate the extent of vertical transmission and follow up of neonates with GBS colonization in order to establish extent of disease development. In our study as the GBS colonization rate among pregnant women in third trimester of pregnancy is low, screening for GBS as a routine component of prenatal care is a procedure of uncertain clinical value.

\section{Recommendations}

$>$ It is recommended to conduct further molecular studies to characterize GBS strains in order to further elucidate the extent of mother to child transmission (vertical transmission) by performing DNA finger printing.

$>$ It is desirable to conduct an extensive study in order to further determine the potential risk factors for GBS colonization that have been frequently cited in the literature such as prolonged rupture of membrane, intrapartum fever, mode of delivery and low birth weight. 
$>$ Serotyping of GBS should be done to develop and implement effective vaccine for prevention of neonatal GBS disease. Serotyping is an effective epidemiological tool for studying GBS.

$>$ Antibiotic resistant GBS may occur with more widespread use of antibiotics. Therefore surveillance of antibiotic resistance patterns among several antimicrobial classes will be important in determining optimal prophylaxis and treatment of GBS infections. Indeed the problem of antibiotic resistance is global. Therefore; health care providers worldwide should be encouraged to join public health authorities, to control the inappropriate use of antibiotics and promote responsible prescribing. This will greatly help to improve prevention and control of drug resistant organisms in communities.

$>$ For the time-being Penicillin should be the preferred choice for treatment of GBS infections, however continuous antimicrobial surveillance is required to monitor trends of resistance.

$>$ It would have an impact on the management of pregnant women before giving birth and their babies if these kind of studies are repeated in many health institutions. So the outcome of these studies can be used in formulating guidelines for the antenatal care.

\section{References}

1. Hood M, Jahney A and Dameron G. Beta hemolytic Streptococcus group-B associated with problems of the perinatal period. Am J Obstet Gynecol. 1961; 82(4): 809-818.

2. Eickhoff $\mathrm{TC}$ et al. Neonatal sepsis and other infection due to group-B beta hemolytic Streptococci. The New Engl J of Med. 1964; 271(24): 1223-1229.

3. Hoogkamp-Korstanje JA, Gerards LJ, Cats BP. Maternal carriage and neonatal acquisition of Group-B Streptococci. J
Infect

Dis.

1982;

145(6):

800-3.

4. Baker CJ, Barrett FF et al. Suppurative meningitis due to Streptococci of Lancefield group-B. A study of 33 infants. The J of Pediatr. 1973; 82(4): 724-729.

5. Barton LL, Feigin RD and Lins R. GroupB BHS meningitis in infants. J Pediatr. 1973; 82(4): 719-723.

6. Wheelver WE. Non-epidemic infections peculiar to the gravid state. Am J Dis Child. 1966; 112: 175.

7. Franciosi RA et al. GBS neonatal and infant infections. The J of Pediatr. 1973 April; 82(4): 707-718.

8. Mhaskar Rita, Sharad S, Srikanth N,Swarnarekha B,Ranjani S. Selective risk factor based screening of pregnant women for group B Streptococcal colonization in a teaching hospital in south India.Indian $\mathbf{J}$ Obstetrics Gynecology 2005; 55(4):33638.

9. Kulkarni AA, Pawar SG, Dharmadhikari CA,Kulkarini RD. Colonization of pregnant women and their new born infants with group B Streptococci. Indian Journal of Medical Microbiology,2001;19(2):1-4.

10. El-Kersh TA, Nuaim LA, Kharfy TA, Shammary FJ,Saleh SS,Zamel FA et al.Detection of genital colonization of group B Streptococci during late pregnancy.Saudi Med J 2002;23(1):56-61.

11. Regan JA, Klebanoff MA, Nugent RP (1991). The epidemiology of group B streptococcal colonization in pregnancy. Vaginal infections and Prematurity Study Group. Obstet Gynecol 77:604-610.

12. Motlova J, Strakova L, Urbaskova P,Sak $\mathrm{P}$, Server T. Vaginal and rectal carriage of Streptococcus agalactiae in the Czech Republic: Incidence,serotypes distribution and susceptibility to antibiotics.Indian $\mathbf{J}$ Med Res,2004;119:84-87. 
13. Nwachukwu NC, Utsalo SJ, Kanu I, Anyanwu EC(2007), Genital colonization of group B Streptococcus at term pregnancy in Calabar,Nigeria. The Internet Journal of Pediatrics and Neonatology 7:2.

14. Orrett FA. Colonisation with group B Streptococci in pregnancy and outcome of infected neonates in Trinidad. Pediatrics Inf 2003;45(3):319-323.

15. Elbardie SM, Mahmoud M, Farid M, (2009) Maternal and neonatal screening for Group B Streptococci by SCP B gene based PCR :a preliminary study. Indian J Med Microbiol 27:17-21.

16. Sobhana Surya Pradeep M, Vishnuvardhana Rao K. A study on prevalence of group B Streptococci as a colonizer in women of reproductive age group.Int $\mathbf{J}$ Med Res Health Sci. 2013;2(4):911-916.

17. Anthony BF and Okada DM,Hobel CJ.Epidemiology of group-B Streptococcus: Longitudinal observations during the pregnancy. The J of Infect Dis. 1978; 137(5): 524-530.

18. Yow MD et al. The natural history of group-B Streptococci colonization in the pregnant women and her offspring I Colonization studies. Am J Obstet Gynecol. 1980; 137(1): 34-38.

19. Vinay Hajare,et al.2012. Antibiogram of Group B Streptococci isolated from the vagina of pregnant women in third trimester of pregnancy.People J.Scientific Res,Vol.5(2).

20. Vijayan Sharmila,et al, Noyal Mariya Joseph, Thirunavukkarasu Arun Babu, Latha Chaturvedula,Sujatha Sistla. Genital tract group B Streptococcal colonization in pregnant women: a South Indian perspective.J Infect Dev Ctries 2011; 5(8): 592-595.

21. Beachler CW, Baker CJ, Kasper DL, Fleming DK, Webb BJ, Yow MD. GroupB Streptococcal colonization and antibody status in lower socioeconomic parturient women. Am J Obstet Gynecol. 1979; 133(2): 171-3.

22. Collado DL et al. Colonization of Mexican pregnant women with group-B Streptococcus. The J of Infect Dis. 1981; 143(1): 134.

23. Tupili Ramya et al, K.H. Vasudeva Naidu, Usham Gangaram. Isolation of Group B Streptococci from Antenatal Women. Int. J. Curr. Microbiol. App. Sci (2016) $5(5): 848-854$.

24. Merenstein CB et al. Group-B hemolytic Streptococcus: Randomized controlled treatment study at term. Obstetrics \& Gynecology. 1980; 55(3): 315-318.

25. Chen K.T, Tuomala R.E, Cohen A.P,Eichenwald E.C, Lieberman E.No increase in rates of early -onset neonatal sepsis by Non group B Streptococcus or ampicillin-resistant organisms.Am J Obstet Gynecol 185,854-858.

26. Schoening T E, Wagner J and Arvand M. Prevalence of erythromycin and clindamycin resistance among Streptococcus agalactiae isolates in Germany, Clin Microbiol Infect.2005 Jul; 11(7):579-82.

27. de Azavedo J.C.S, McGavin M, Duncan C, Low D. E. \& McGeer. A.(2001). Prevalence and Mechanisms of Macrolide Resistance in Invasive and Non invasive Group B Streptococcus Isolates from Ontario, Canada. Antimicrob Agents Chemother 45, 3504-3508.

28. Simoes, J. A, Aroutcheva, A, Hemler I. \& Faro S. (2004).Antibiotic resistance patterns of group B streptococcal clinical isolates. Infect Dis Obstet Gynecol 12, 1-8.

29. Mercer B. M, Carr T. L, Beazley D. D, Crouse D. T. \& Sibai B. M. (1999).Antibiotic use in pregnancy and drug-resistant infant sepsis.American Journal of obstetrics \& gynecology 181, 816-821. 
30. Stylianopoulos A, Kelly N. \& Garland S. (2002).Is penicillin and/or erythromycin resistance present in clinical isolates of group B streptococcus in our community? Aust N Z J Obstet Gynaecol 42, 543-544.

31. Werno A. M. \& Murdoch D. R. (2003).Letters to the Editor Antimicrobial susceptibilities of Group B Streptococci in New Zealand. Antimicrob Agents Chemother.

32. Daley A. J. \& Garland S. M. (2004). Prevention of neonatal group B streptococcal disease: Progress, challenges and dilemmas. J Paediatr Child Health 40, 664-668.

33. James D.C (2001). Maternal screening and treatment for group B Streptococcus.J Obstet Gynecol Neonatal Nurs 30,659666.

34. Desjardins M, Delgaty K. L, Ramotar K, Seetaram C. \& Toye B. (2004).Prevalence and mechanisms of erythromycin resistance in group A and group B Streptococcus: implications for reporting susceptibility results. J Clin Microbiol 42, 5620-5623.

35. Acikgoz Z. C, Almayanlar E, Gamberzade S. \& Gocer S. (2004).Macrolide resistance determinants of invasive and Noninvasive group B streptococci in a Turkish hospital. Antimicrob Agents Chemother 48, 14101412.

36. Arisoy A. S, Altinisik B, Tunger O, Kurutepe S. \& Ispahi C. (2003).Maternal carriage and antimicrobial resistance profile of group B Streptococcus. Infection 2003, 4.

37. Figueira-Coelho J, Ramirex M, Salgado J. H. \& Melo-Cristino, J.(2004). Streptococcus agalactiae in a large Portuguese teaching hospital: antimicrobial susceptibility, serotype distribution, and clonal analysis of macrolide-resistant isolates. Microb Drug Resist 10, 31-36.
38. Fluegge K, Supper S, Siedler A \& Berner R. (2004).Antibiotic susceptibility in neonatal invasive isolates of Streptococcus agalactiae in a 2-year nationwide surveillance study in Germany. Antimicrob Agents Chemother 48, 4444-4446.

39. Lopardo H. A, Vidal P, Jeric P, Centron D, Paganini H, Facklam R. R, Elliot J. \& Group A. S. S.(2003). Six-month multicentre study on invasive infections due to group B streptococci in Argentina. J Clin Microbiol 41, 4688-4694.

40. Radhakrishnan S, Brahmadathan K. N, Mathai E, Jesudason M. V. \& Lalitha M. K.(1995).Changing patterns of group B streptococcal serotypes associated with human infections. Indian J Med Res 102, 56-59.

41. Tsolia M, Psoma M, Gavrili S, Petrochilou V, Michalas S, Legakis N \& Karpathios T (2003).Group B streptococcus colonization of Greek pregnant women and neonates: prevalence, risk factors and serotypes. Clin Microbiol Infect 9, 832-838.

42. Andrews J.I, Diekema D.J \& Hunter S.K(2000). Group B Streptococci causing neonatal bloodstream infection: antimicrobial susceptibility and serotyping results for SENTRY centres in the Western Hemisphere. Am j Obstet Gynecol 183,859-862. 